\title{
Modern Radiotherapy and Risk of Cardiotoxicity
}

\author{
Efstratios Koutroumpakis ${ }^{a}$ Nicolas L. Palaskas ${ }^{b}$ Steven H. Lin ${ }^{c}$ Jun-ichi Abe ${ }^{b}$ \\ Zhongxing Liao $^{c}$ Jose Banchs ${ }^{b}$ Anita Deswal $^{b}$ Syed Wamique Yusuf ${ }^{b}$ \\ aDivision of Cardiovascular Medicine, University of Texas Health Science Center, Houston, TX, USA; \\ ${ }^{b}$ Department of Cardiology, University of Texas MD Anderson Cancer Center, Houston, TX, USA; \\ 'Department of Radiation Oncology, University of Texas MD Anderson Cancer Center, Houston, TX, USA
}

\section{Keywords}

Radiotherapy · Cardiotoxicity · Radiation-induced heart disease

\section{Abstract}

Despite the advancements of modern radiotherapy, radiation-induced heart disease remains a common cause of morbidity and mortality amongst cancer survivors. This review outlines the basic mechanism, clinical presentation, risk stratification, early detection, possible mitigation, and treatment of this condition.

(c) 2020 S. Karger AG, Basel

\section{Introduction}

Radiation therapy (RT) is currently administered to about half of the patients with cancer either as a neoadjuvant or adjuvant treatment [1]. Radiation-induced heart disease (RIHD) is a unifying term used to describe all cardiac complications related to RT. Pericardial disease, ischemic heart disease, nonischemic cardiomyopathy, valvular disease, conduction abnormalities, and arrhyth-

karger@karger.com

(c) 2020 S. Karger AG, Basel

www.karger.com/che

Karger" mias have all been independently linked to chest radiation [2-5]. Advancements in cancer therapy have led to improved survival, which in turn has led to increased recognition and prevalence of RIHD [6,7]. Despite improved RT techniques and modalities that decrease the total administered radiation dose, RIHD remains a common cause of morbidity and mortality among cancer survivors [8-10]. Therefore, prevention, early identification, and prompt treatment are essential in the management of RIHD. In this review article, we focus on risk factors, basic pathophysiological mechanisms, clinical manifestations, methods for early detection, possible mitigation, prevention and treatment of RIHD.

\section{Risk Factors}

Risk factors contributing to the development of RIHD can be grouped into radiation specific and patient specific (Table 1).

\section{Radiation-Specific Risk Factors}

Radiation-specific risk factors include total dose of radiation, mean cardiac dose, volume of the heart irradi- 
Table 1. Risks factors associated with the development of RIHD

\begin{tabular}{ll}
\hline Radiation specific & Patient specific \\
\hline $\begin{array}{l}\text { Total dose of radiation } \\
\text { Mean cardiac dose }\end{array}$ & $\begin{array}{l}\text { Treatment at a young age } \\
\text { Traditional cardiovascular risk factors (hypertension, diabetes, } \\
\text { obesity, smoking, and hyperlipidemia) }\end{array}$ \\
$\begin{array}{l}\text { Frequency of radiation treatments } \\
\text { Proximity of the tumor to the heart } \\
\text { Volume of heart muscle exposed }\end{array}$ & $\begin{array}{l}\text { Genetic susceptibility } \\
\text { Cardiac avoidance technique }\end{array}$ \\
\hline
\end{tabular}

RIHD, radiation-induced heart disease.

ated, proximity of the primary radiated tumor to the heart, fractions of radiation treatments, and lack of cardiac avoidance techniques $[4,11]$. The radiobiologic equivalent dose and the linear energy transfer describe the ionization potential of the radiation and therefore the potential for injury to normal tissue [12]. Both higher radiobiologic equivalent dose (which is determined by the dose and fractions delivered) and linear energy transfer (based on whether it is photons or particles being used) will determine the extent of damage [12]. In general, thoracic RT that exceeds $30 \mathrm{~Gy}$ is considered a high dose that leads to high mean cardiac dose and places patients at increased risk for RIHD $[4,13]$. In a retrospective study of 2,232 patients with Hodgkin's lymphoma who received RT, it was found that total doses of $>30$ Gy resulted in a 3.5-fold higher risk for cardiac death compared to a matched general population [4]. In addition to the total RT dose, mean heart dose and volume are also independent risk factors for RIHD [4, 14]. A pooled analysis of 6 trials found that patients with nonsmall cell lung cancer, who developed symptomatic cardiotoxicity, had received a mean cardiac dose of $20.4 \mathrm{~Gy}$, as opposed to $10.0 \mathrm{~Gy}$ received by those who did not develop cardiotoxicity [14]. Mean heart doses of $<10 \mathrm{~Gy}$, 10-20 Gy, and >20 Gy were associated with 2-year riskadjusted cardiac event rates of 4,7 , and $21 \%$, respectively [14]. In addition, $\mathrm{LV}$ volume receiving $>5$ Gy was significantly associated with cardiac events including symptomatic pericardial effusion, pericarditis, myocardial infarction, unstable angina, and heart failure [14]. Furthermore, the location and laterality of the radiated tumor in terms of radiation delivery is of significant clinical consequences. A meta-analysis of patients with breast cancer receiving left-sided RT demonstrated a relative risk of 1.29 (95\% CI: 1.13-1.48) for coronary artery disease (CAD) and 1.22 (95\% CI: 1.08-1.37) for car- diac death compared to those receiving right-sided RT [15]. Typically, radiation doses are fractionated into smaller daily doses of $<2 \mathrm{~Gy}$ as it has been found that fractions of $>3$ Gy are associated with increased cardiotoxicity, particularly pericardial effusions [16]. Cardiac shielding techniques have also been developed over the years from initial subcarinal blocking that was effective in limiting cardiac RT dose [4] to newer cardiac avoidance techniques such as deep inspiratory breath-holds [17] and intensity-modulated RT using multileaf collimator modification $[18,19]$.

\section{Patient-Specific Risk Factors}

Patient-specific risk factors include treatment at a younger age, hypertension, diabetes, smoking history, obesity, dyslipidemia, and prior history of cardiac disease $[2,3,20]$. Younger patients are at increased risk for developing RIHD. In a retrospective cohort of 2,524 Dutch patients treated for Hodgkin's lymphoma, it was found that patients younger than 25 years had a 4.6 - to 7.5-fold increased risk of CAD [3]. While traditional cardiac risk factors such as hypertension, dyslipidemia, and diabetes are known to increase the risk of RIHD [21], smoking, in particular when added to RT, conferred a 3 times higher hazard for myocardial infarction [22]. Additionally, experimental data suggest that genetic variations, including mutations in genes involved in DNA repair pathways, increase cellular radio sensitivity [23]. Concurrent use of cardiotoxic chemotherapeutic agents, particularly anthracyclines, is another risk-enhancing factor for the development of RIHD [2, 3, 24, 25]. Establishment of models for early risk stratification will allow identification of high-risk patients who would potentially benefit from modification of RT or from preventive treatment.
Koutroumpakis/Palaskas/Lin/Abe/Liao/ Banchs/Deswal/Yusuf 
Fig. 1. The pathophysiologic cascade of RIHD. RIHD, radiation-induced heart disease.

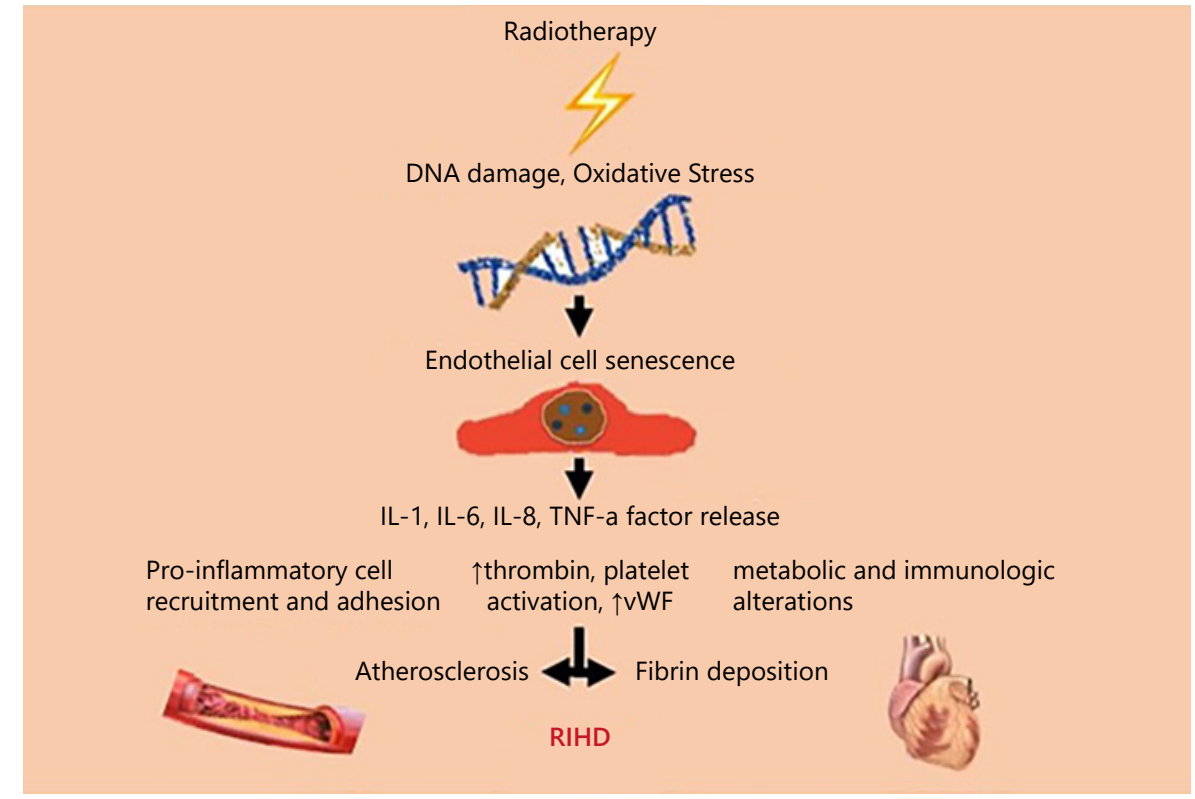

\section{Pathophysiology}

The initial key pathophysiologic step for development of RIHD is endothelial cell senescence from DNA damage and oxidative stress caused by radiation [26-29]. Senescent endothelial cells release proteins and proinflammatory cytokines, which activate a milieu of subsequent pathways [29]. Increased levels of IL-1, IL-6, IL-8, and TNF- $\alpha$ as well as reactive oxygen species (superoxide and peroxynitrite) have all been implicated as mediators of the subsequent processes [29-31]. Proinflammatory cell recruitment and adhesion follows, mediated by elevated levels of selectins, integrins, and immunoglobulin superfamily members [32]. Elevated circulating levels of vWF as well as downregulation of thrombomodulin, which leads to an increase in free thrombin and activation of platelets, are associated with the development of a prothrombotic state [29]. Finally, metabolic and immunologic alterations including increased glycolysis, altered mitochondrial oxidation and lipid metabolism, and immune system activation mediated by toll-like receptors and the chemokine receptor CXCL6 contribute to the disease $[33,34]$. The product of the above pathways is accelerated atherosclerosis, fibrin deposition, intimal thickening, lipid accumulation, inflammation, and thrombosis. The spectrum of CAD, cardiomyopathy, pericardial disease, valvular disease, and conduction abnormalities is collectively described as RIHD. Figure 1 illustrates the pathophysiologic cascade of RIHD.

\section{Clinical Manifestations}

Radiation can affect all layers of cardiac tissue and cause a wide range of clinical manifestations [35-37]. Acute inflammation of the pericardium or myocardium can occur during or shortly after radiotherapy $[35,36,38$, 39]. The incidence of acute pericarditis and myocarditis though is rare with modern radiation techniques and lower fractions of RT. They usually manifest with symptoms of chest pain with pleuritic features or dyspnea. Myocardial inflammation can also induce arrhythmias, which may manifest as syncope or palpitations. Late cardiac effects, such as CAD, valvular disease, and conduction abnormalities, can present years or decades after radiotherapy $[35,36,39]$. Overlap of more than one pathologies is common (Table 2).

\section{Pericardial Disease}

The most common cardiac manifestation of RIHD is pericardial disease, which may manifest early, as acute pericarditis (Fig. 2), or late, in the form of pericardial effusion and/or constrictive pericarditis (Fig. 3) [40]. In a study of 294 asymptomatic patients with Hodgkin's lymphoma, who received an RT dose of at least $35 \mathrm{~Gy}$, pericardial thickening by echocardiography was found in $21 \%$, compared to only $2 \%$ of patients in the Framingham Heart Study, who were used as controls [41]. In this study, the protocol included a left ventricular block after $15 \mathrm{~Gy}$ and a subcarinal block that excluded most of the heart 


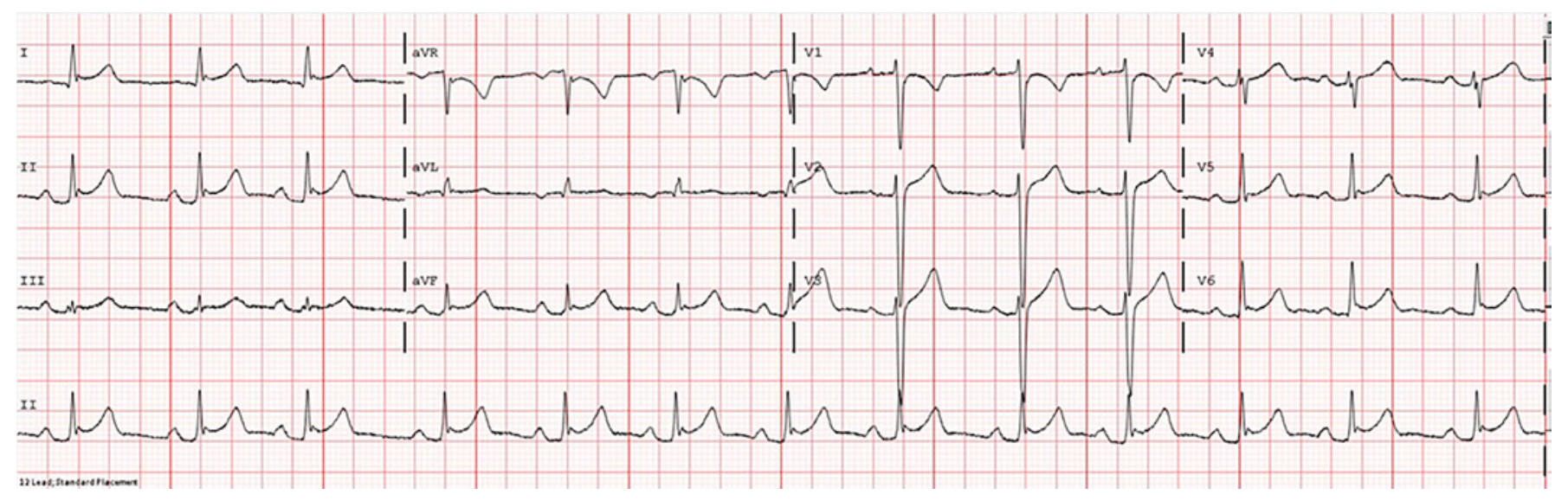

Fig. 2. A 12-lead ECG showing pericarditis with PR segment depression and generalized concave ST elevation in all leads except aVR which shows ST depression. ECG, electrocardiogram.

Table 2. Clinical manifestations of RIHD

Key characteristics

Pericardial disease

Pericarditis

Constrictive pericarditis

Asymptomatic thickening and small pericardial effusion

Large pericardial effusion and cardiac tamponade

Coronary vasculopathy

Both large epicardial arteries and arterioles are affected

Coronary lesions predominantly in the proximal parts of the epicardial arteries

Acute coronary syndromes or stable ischemic heart disease and ischemic cardiomyopathy

Nonischemic cardiomyopathy

Diffuse fibrosis that does not follow any coronary distribution pattern

Diastolic and in late stages systolic left ventricular dysfunction

Conduction abnormalities

Fibrosis affects the conduction system

Infranodal and right bundle branch blocks are most common due to anterior position of the right bundle

Valvular disease

Thickening and calcification

Typically aortic and mitral valves

Manifests either as stenosis or regurgitation

Annulus of the valve, subvalvular apparatus, and aortomitral curtain might be involved

RIHD, radiation-induced heart disease.

after 30 Gy [41]. In a study, in which RT was given in a dose of 1.8-2.0 Gy per day, for a total of 60 Gy over 6 weeks, among 214 patients with esophageal cancer treated with concurrent chemoradiation therapy, $36 \%$ developed pericardial effusion between 2 and 40 months after RT, while $8.4 \%$ developed symptomatic pericardial effusion [42]. Patients who develop pericardial effusion following RT should be monitored closely since it may progress to large effusion and cardiac tamponade [43].
Figure 2 shows a 12-lead electrocardiogram demonstrating acute pericarditis related to RT. The patient is a 58 -year-old woman with lung cancer who presented 2 weeks after RT with classic symptoms of pericarditis. She was treated with nonsteroidal anti-inflammatory drug (ibuprofen), colchicine, and steroid with full recovery and no recurrence.

Figure 3 shows an echocardiogram showing pericardial effusion related to RT. The patient had lung cancer 


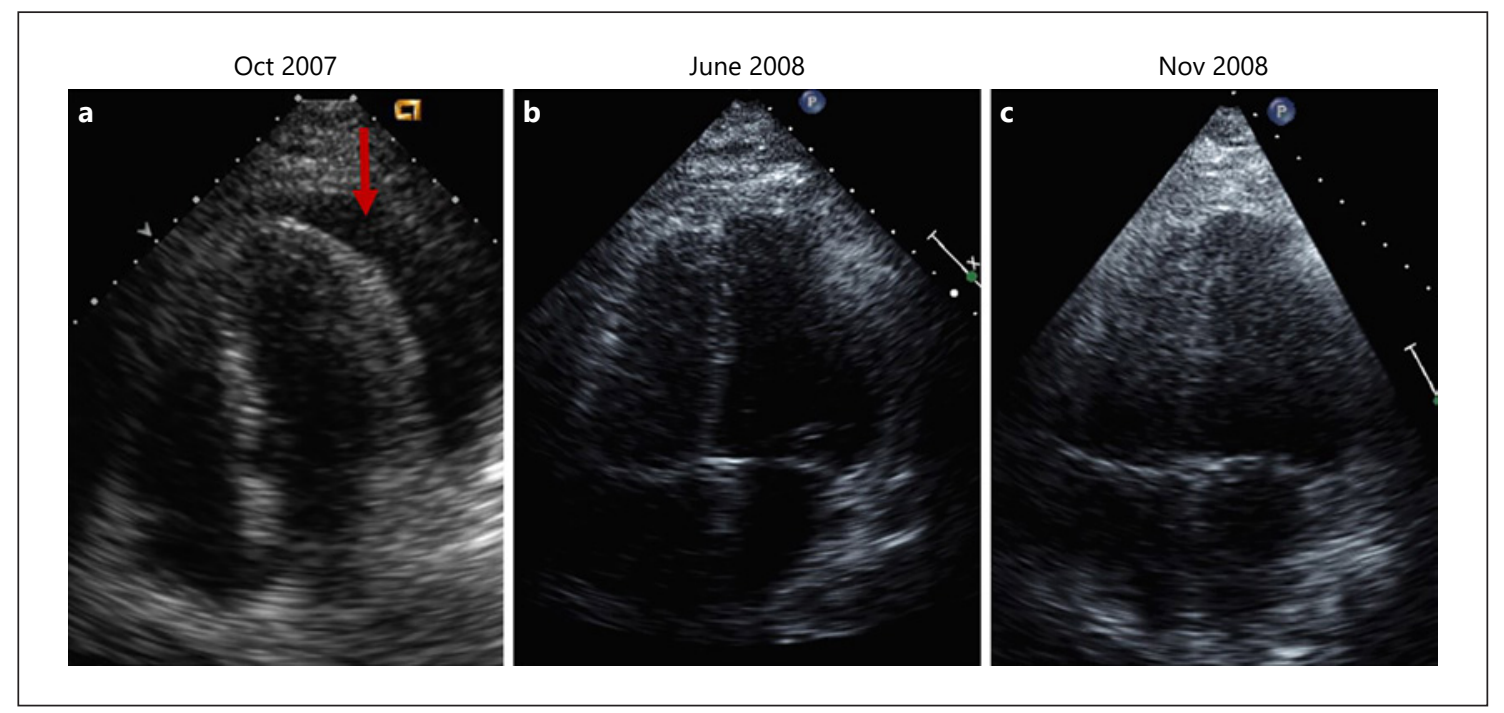

Fig. 3. a A moderate to large pericardial effusion. b, $\mathbf{c}$ No reaccumulation of pericardial fluid.

with disease progression in the mediastinum, for which he was treated with a cumulative dose of 66 Gy RT. Routine chest computed tomography scan a year later showed a large pericardial effusion for which he underwent pericardiocentesis. Pericardial fluid analysis showed only reactive mesothelial cells in a background of acute and chronic inflammation with no evidence of malignancy. Follow-up echocardiograms showed no recurrence of pericardial effusion.

\section{Ischemic Heart Disease}

Radiation-induced CAD and accelerated atherosclerosis can present as either angina, acute coronary syndrome, or ischemic cardiomyopathy and heart failure. The coronary lesions are predominantly located in the ostia or the proximal portions of the epicardial vessels $[40,44]$. In particular, the anterior part of the heart is more commonly affected by RT, thus resulting in high radiation doses to the left anterior descending artery [45]. In addition to the large epicardial vessels, the small arteries are also affected. The majority of the patients may remain asymptomatic for years $[41,46]$. In a large population-based study of breast cancer patients, it was found that the rate of major coronary events increased by $7.4 \%$ (95\% CI: 2.9-14.5, $p<0.001$ ) for each increase of $1 \mathrm{~Gy}$ in the mean radiation dose delivered to the heart [47]. The risk started to increase within the first 5 years and extended to at least 20 years following exposure [47]. In this study, virtual simulation and CT planning were used for the reconstruction of radiotherapy fields on a CT scan, and radiation doses to the structures of interest were then estimated [47].

The relative risk of death from myocardial infarction is estimated to be double in patients exposed to chest RT compared to the general population. In a cohort of 7,033 patients with Hodgkin's lymphoma treated with RT, the standardized mortality ratio from myocardial infarction was 2.5 ( $95 \% \mathrm{CI}=2.1$ to 2.9 ) with an absolute excess risk of 125.8 per 100,000 person-years compared to the general population of England and Wales [48].

Treatment of radiation-induced CAD with common revascularization techniques is challenging. When compared to CAD in nonradiated patients, the mortality is higher in RT-induced CAD, regardless of whether the patients are treated with percutaneous or surgical revascularization [49]. In an observational study of 314 patients treated at Cleveland Clinic, mortality after percutaneous coronary intervention (PCI) for radiation-induced CAD was higher compared to mortality after PCI for typical atherosclerotic CAD [49]. Independent predictors of mortality included balloon angioplasty or bare-metal stent placement, SYNTAX (Synergy between PCI with Taxus and Cardiac Surgery) score of $\geq 11$, New York Heart Association functional class $\geq 3$, history of smoking, and age $\geq 65$ years [49].

Compared to general population, patients with prior chest RT who undergo cardiac surgery, including coronary artery bypass grafting, have worse outcomes. In a case-control study of patients with RIHD, mortality rates after any cardiac surgery were $72 \%$ at 7.6 years in RT- 


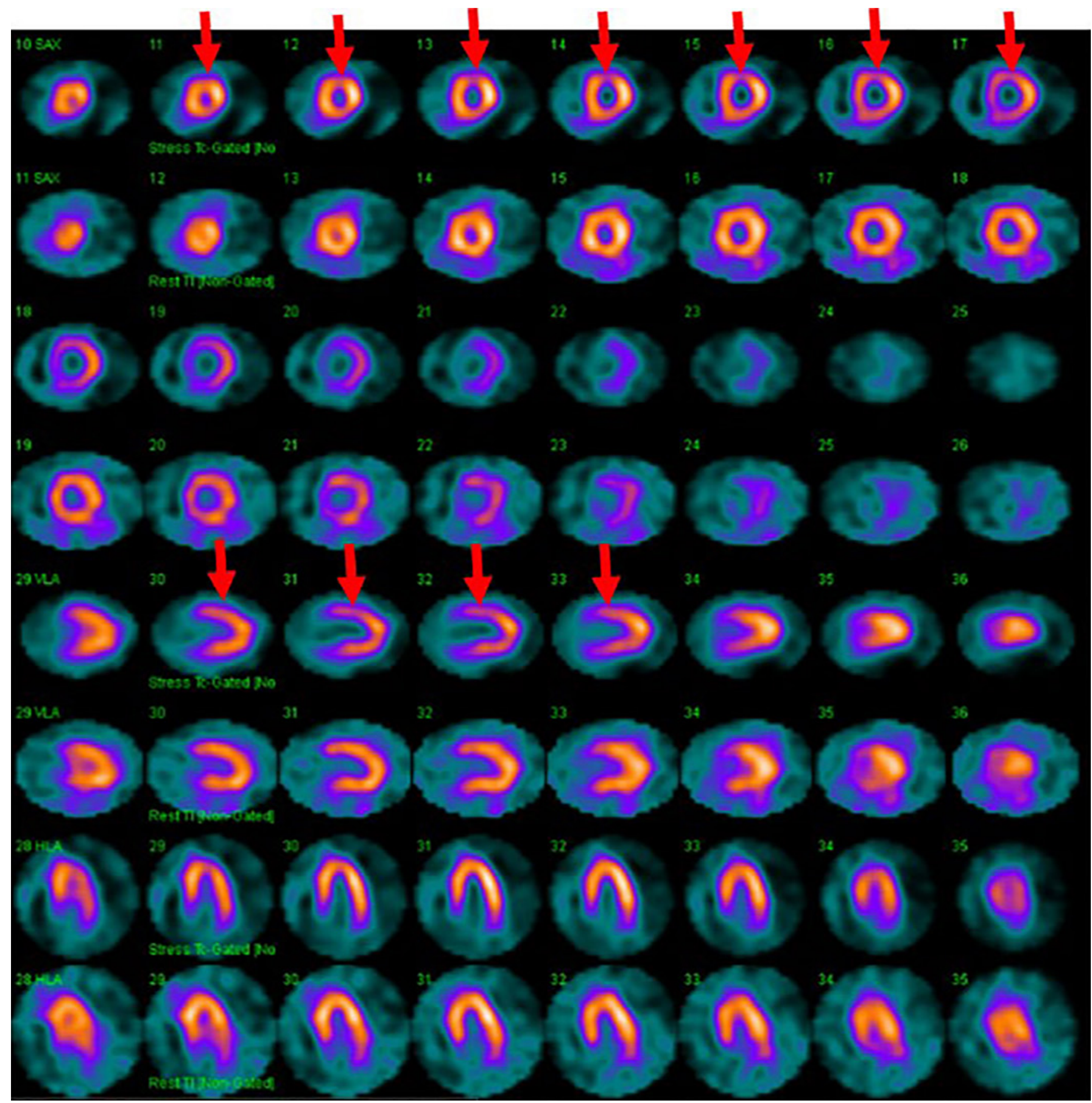

Fig. 4. Myocardial perfusion study showing small- to moderate-sized reversible perfusion abnormality in the anterior wall. The arrow points to the perfusion defects.

exposed patients versus $45 \%$ in controls $(p<0.001)$, while mortality rates after coronary artery bypass grafting, specifically, were 46 versus $28 \%$, respectively [50]. Furthermore, graft patency failure and surgical complications including sternal dehiscence and infection rates are in- creased in patients with prior RT compared to the general population [51]. Due to the above challenges, as well as the frequent presence of concomitant valvular and pericardial disease, any revascularization attempts in patients with prior RT should be planned very carefully. A 

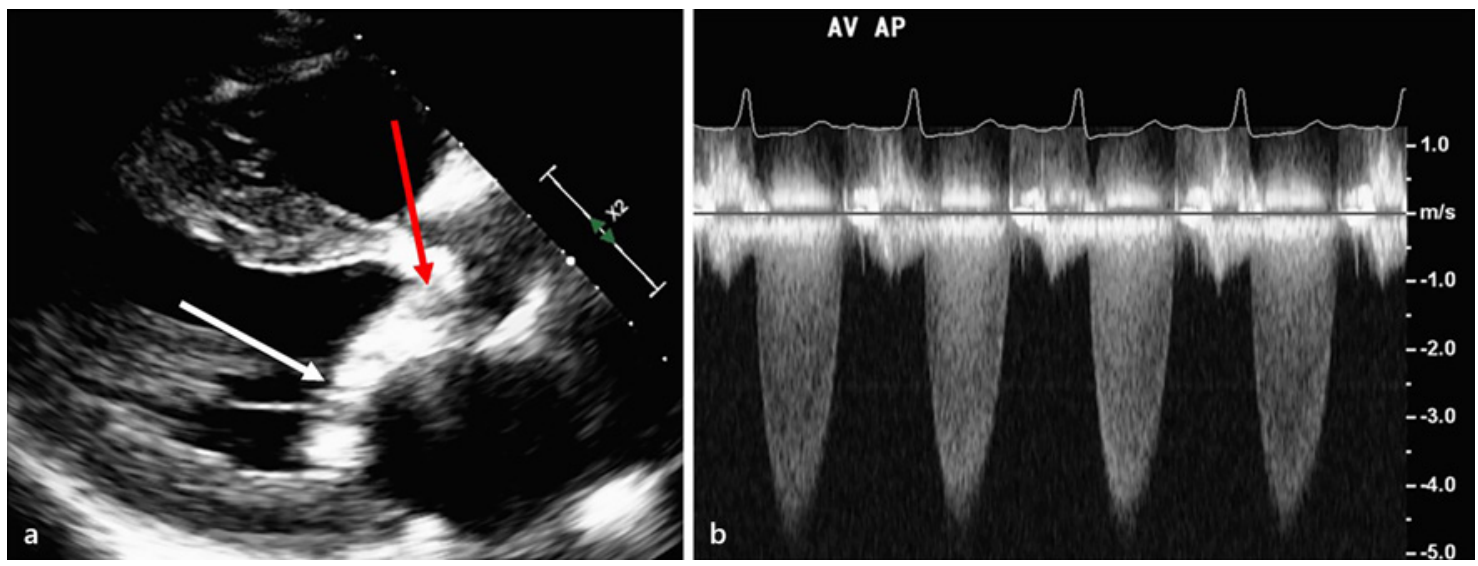

Fig. 5. a Echocardiogram shows severely calcified aortic and mitral valves causing aortic and mitral stenosis. b Doppler across aortic valve shows severe aortic stenosis and aortic regurgitations. The red arrow points towards the aortic valve and the white arrow shows the mitral valve.

personalized treatment approach involving the heart team model and a multidisciplinary team with experience in managing these patients is crucial.

Figure 4 shows the myocardial perfusion scan showing ischemia in the anterior wall, in a 41-year-old man presenting with chest pain 5 years after completion of RT for Hodgkin's lymphoma.

\section{Nonischemic Cardiomyopathy}

RT causes myocardial damage with resultant fibrosis and development of diastolic dysfunction, which may ultimately lead to restrictive cardiomyopathy or progress to systolic dysfunction $[39,52]$. Myocardial fibrosis is usually diffuse and does not follow any coronary distribution pattern although fibrosis related to concurrent CAD is also present $[5,46]$. Survivors of Hodgkin's disease who had previously received RT were found to have an increased incidence of heart failure compared to the general population (standardized incidence ratio of 4.9) translating to 25.6 excess cases of heart failure per 10,000 patients/year [25]. In this study, the radiotherapy techniques used were different over the years; for example, in the 1960 s, patients were treated with cobalt- 60 or orthovoltage therapy, whereas from the 1970s onward, linear accelerators were used (usually 8-MV photons), but the vast majority of patients had received a classical mediastinal field radiation [25].

Patients can present with dyspnea, fatigue, edema, orthopnea, and/or paroxysmal nocturnal dyspnea. In a study of relatively young patients with Hodgkin's disease (only $33 \%$ of the patients in this study were $>50$ years of age), who were treated with mediastinal irradiation, the prevalence of diastolic dysfunction was several-fold greater than in community studies [53].

Heart failure in patients with previous RT could be multifactorial with a combination of primary myocardial damage, constrictive pericarditis, and ischemic heart disease. Therefore, clinical evaluation and appropriate investigations are needed to differentiate the possible causes of heart failure in these patients.

\section{Conduction Abnormalities and Arrhythmias}

Fibrosis can also affect the conduction system leading to the development of arrhythmias and heart block with symptoms of lightheadedness and syncope. Abnormal electrocardiogram is present in up to $75 \%$ of long-term survivors who have received mediastinal radiation [54]. In this study, the radiation techniques included 4- or 6-MV radiation source, equal weighting of daily fraction from anterior and posterior portals, $<2$ Gy daily fraction size, and similar heart and lung blocking [54]. The most common conduction abnormalities are infranodal and right bundle branch blocks. This is due to the anterior position of the right bundle, which makes it more susceptible to damage by RT [55]. There are reports of advanced atrioventricular block including complete heart block requiring permanent pacemaker implantation although this is rare [56]. Both supraventricular and ventricular arrhythmias are more prevalent in children and young adults who have received cardiac radiation [55].

\section{Valvular Disease}

Chest RT is associated with thickening and calcification of the cardiac valves, typically involving the aortic 
and mitral valves [41]. Radiation-induced valvular disease is usually a late manifestation and presents with symptoms and signs of heart failure due to either valvular stenosis or regurgitation [41]. The most common valvular abnormality is aortic regurgitation with $\sim 60 \%$ of asymptomatic patients who have received radiation $>20$ years prior having at least mild aortic regurgitation [41]. The incidence of aortic stenosis ( $16 \mathrm{vs.} 0 \%, p$ value 0.0008 ) and moderate-to-severe tricuspid regurgitation ( 4 vs. $0 \%, p$ value 0.06 ) is also more common amongst patients who had received RT $>20$ years earlier, when compared to those receiving $\mathrm{RT}$ within the previous 10 years [41].

Frequently, in addition to the valves, surrounding structures including the annulus of the valve, subvalvular apparatus, and aorto-mitral curtain are involved [40, 41]. Calcification of the aortic valve, mitral valve, or intervalvular fibrosa is found in up to $90 \%$ of patients who have been treated with radiation $>20$ years ago [41]. This increased calcification in the subvalvular and supravalvular structures creates technical difficulties during valve replacement either by percutaneous or surgical methods. In a study of 173 patients with radiation-induced valvular disease who underwent cardiac surgery, aorto-mitral curtain thickness of $>0.6 \mathrm{~cm}$ independently predicted mortality [57]. In a smaller report of 37 patients who underwent valvular replacement for radiation-induced valvular disease, the rate of in-hospital complications was 59\%, in-hospital death was $14 \%$, and 1-year mortality was $24 \%$. Transcatheter intervention is a reasonable alternative to surgery, particularly in case of isolated valve disease, with shorter in-hospital stay (7 vs. 14 days) and lower in-hospital mortality ( 6 vs. $25 \%, p=0.19$ ). One-year mortality was similar (18 vs. $25 \%, p=0.4$ ) [58].

Figure 5 shows valvular heart disease in a 52 -year-old man who presented with chest pain and dyspnea 35 years after completion of RT for Hodgkin's lymphoma.

\section{Carotid Disease}

Radiotherapy is known to cause both asymptomatic and symptomatic carotid artery disease $[59,60]$. An increased risk of transient ischemic attack or stroke has been documented in 5-year survivors of Hodgkin's lymphoma [61]. As extensive area of the neck is usually radiated, RT often produces carotid lesions that are more diffuse, involving long arterial segments than the traditional bifurcation stenosis [60]. Due to extensive fibrosis, these patients may be more suitable for carotid stenting as opposed to surgical carotid endarterectomy. Carotid artery rupture following $\mathrm{RT}$ has also been reported [62].

\section{Autonomic Dysfunction}

Thoracic RT has also been associated with autonomic dysfunction $[54,63]$. In 1 study, $~ 27 \%$ of patients with previous mantle cell radiation had a blunted blood pressure or heart rate response to exercise, suggesting autonomic dysfunction [54]. Another study of Hodgkin's lymphoma survivors demonstrated that resting tachycardia and abnormal heart rate recovery following stress were more common in patients treated with RT compared to controls (odds ratios: 3.96 [95\% CI: 2.52-6.23] and 5.32 [95\% CI: 2.94-9.65], respectively) [63]. In these patients, presence of autonomic dysfunction was associated with an increased all-cause mortality [63].

\section{Early Detection}

Several serum biomarkers and imaging modalities have been proposed for early detection of RIHD. Thus far, the readily available biomarkers, such as troponin and brain natriuretic peptide, have not been validated in predicting the development of RIHD [64-68]. Two other biomarkers, namely, placental growth factor and growth differentiation factor 15 , were found to be elevated in patients with lymphoma and lung cancer exposed to a higher mean cardiac dose [64]. Since placental growth factor contributes to angiogenesis and atherogenesis and growth differentiation factor 15 is a cytokine secreted in response to tissue injury, inflammation, and oxidative stress, the above observation provides insights into the pathophysiology of RIHD. Further studies need to confirm their value as predictors of RIHD before its use in clinical practice.

Due to widespread use and cost effectiveness, screening echocardiography has been proposed as the imaging modality of choice for the early detection of asymptomatic RIHD [69]. In a prospective study of patients receiving thoracic radiation, at 1 year after completion of RT, there was an association between the mean and maximum LV dose and a decrease in left ventricular ejection fraction (57.6-56.4\%) as well as worsening global longitudinal myocardial strain $(-17.6$ to -17.3$)$ [70]. Further studies in patients with breast cancer have shown a worsening in left ventricular strain as early as 2 months after RT [71, 72]. Whether these echocardiographic findings correlate with subsequent development of clinical RIHD and the appropriate timing of surveillance echocardiography remain to be determined.

Coronary calcium score (CAC) is a useful tool for detection of preclinical atherosclerosis and independently predicts future cardiovascular events $[11,73]$. Since all
Koutroumpakis/Palaskas/Lin/Abe/Liao/ Banchs/Deswal/Yusuf 
patients who receive chest RT undergo CT scans for diagnostic, treatment, or surveillance purposes, CAC may serve as an inexpensive, practical imaging modality for early detection of atherosclerotic RIHD. However, the typical chest CT scans do not have the same number of slices through the heart compared with the dedicated CAC study and may therefore underestimate the calcium score. Furthermore, even though CAC can detect preclinical coronary atherosclerosis, it may not be useful for the detection of the other forms of RIHD (nonischemic cardiomyopathy, valvular disease, conduction abnormalities, and pericardial disease).

Single-photon emission computed tomography myocardial perfusion imaging has been used in some studies as a tool for early detection of myocardial ischemia after $\mathrm{RT}$ in asymptomatic individuals. In a small prospective study by Hardenbergh et al. [74], about $60 \%$ of women with left-sided breast cancer developed new perfusion defects 6 months after RT. A subsequent larger study from the same institution confirmed the high prevalence of perfusion defects after RT ( $40 \%$ after 2 years) and showed that perfusion defects were correlated with left ventricular wall motion abnormalities [37].

Current recommendation is for screening echocardiogram 5 years after chest radiation in high-risk patients and 10 years in the other patients [69]. Functional noninvasive stress test is recommended 5-10 years after chest radiation in high-risk patients [69].

Although strong evidence and clinical data to guide post-RT cardiac surveillance is lacking and recommendations are based on expert opinions, comprehensive screening and long-term routine follow-up for RIHD, especially of high-risk patients, seem to be prudent, given the high prevalence and long latency period between exposure and onset of the disease [75]. The above is reflected in the consensus statement by the European Association of Cardiovascular Imaging, the American Society of Echocardiography [69], and the guidelines published by the American Society of Clinical Oncology (ASCO), the Canadian Cardiovascular Society, and the European Society of Cardiology (ESC) [13, 76, 77].

\section{Prevention and Mitigation of RIHD}

Minimizing cardiac exposure to radiation is essential in reducing the risk of RIHD [14, 78, 79]. Personalized protocols of RT with adjustments in total dose and frequency of therapies based on risk, targeted image-guided $\mathrm{RT}$ with reduction in radiation field and volume, respira-

Cardiotoxicity of Radiotherapy tory motion management, and improvement in conformality with intensity-modulated RT and proton beam therapy are currently used methods for prevention of RIHD [80-83].

Radiation doses have been fractionated into daily doses smaller than 2 Gy since higher doses have been associated with cardiotoxicity. In a multicenter study of $57 \mathrm{pa}-$ tients with esophageal cancer treated with RT, all patients who developed nonmalignant pericardial effusions had received RT with 3.5 Gy daily fractions [16]. Cardiac avoidance techniques have evolved over the years limiting radiation exposure to the heart and decreasing the incidence of RIHD. In a large study of 2,232 patients with Hodgkin's disease followed for 9.5 years, subcarinal blocking reduced the relative risk of cardiac disease, including heart failure, pericarditis or pancarditis, cardiomyopathy, or valvular heart disease from 5.3 (CI: 3.1-7.5) to 1.4 (CI: 0.6-2.9), although it did not decrease the relative risk of acute myocardial infarction (RR: 3.7 vs. 3.4) [4]. Among 89 patients with left-sided breast cancer enrolled in the SAVE-HEART study, the use of deep inspiration breath-hold reduced mean heart radiation doses by $35 \%$ (interquartile range: $23-46 \%$ ) as compared to free breathing, which translated to a greater reduction in expected years of life lost due to RIHD (0.07 vs. 0.11 years, respectively) [17]. In another study, intensity-modulated RT and moderate deep inspiration breath-hold significantly reduced heart V30 from 19.1 to $3.1 \%(p<0.0004)$ [19]. In a more recent study of 49 patients with left-sided breast cancer, a multileaf collimator modification technique was tested and resulted in significant reduction in the mean left anterior descending artery (LAD) dose by 7.0 Gy, the mean LAD planning risk volume dose by 5.9 Gy, the maximum LAD dose by $12 \mathrm{~Gy}$, and the mean heart dose by $0.73 \mathrm{~Gy}$, whilst maintaining breast and boost volume dosimetry [18]. Furthermore, a recently published phase IIB randomized clinical trial of 145 patients compared total toxicity burden and progressionfree survival between proton beam therapy and intensitymodulated RT for advanced esophageal cancer. The trial was stopped early since in the interim analysis proton beam therapy had a significantly lower mean total toxicity burden compared to intensity-modulated RT while maintaining similar progression-free survival [84]. Although these contemporary techniques appear to have decreased the incidence of cardiac complications related to $\mathrm{RT}$, residual risk remains [78].

In addition to minimizing the exposure of the heart to RT (primary prevention), pharmacologic therapy might also have a role after exposure (secondary prevention). 
There is some evidence that metformin may be beneficial in subjects undergoing RT $[85,86]$. A retrospective national cohort study based on the Taiwan Cancer Registry, including 6,993 women with early-stage breast cancer who received adjuvant breast RT, showed that metformin use during RT reduced the risk of heart failure and CAD (adjusted hazard ratio: 0.789, 95\% CI: 0.645-0.965, $p=$ 0.021) [85]. However, large prospective confirmatory studies are needed before advocating its use in clinical practice. Statins may be beneficial as limited evidence from animal studies and retrospective human studies suggest that statins might prevent cardiac fibrosis and reduce cerebrovascular and cardiovascular events when administered after chest RT $[87,88]$. A large retrospective study of 5,718 patients treated with RT for thoracic or head and neck cancers reported that statin use after RT was associated with a significant reduction of stroke by $32 \%$ (hazard ratio $=0.68,95 \%$ CI: $0.48-0.98, p=0.0368$ ) and a trend of reducing the composite of cerebrovascular (transient ischemic attack and fatal or nonfatal stroke) or cardiovascular events (fatal or nonfatal myocardial infarction) (hazard ratio $=0.85,95 \%$ CI: $0.69-1.04, p=$ 0.0811 ) [87]. Colchicine has also been proposed as a prophylactic treatment option to mitigate the cardiotoxic effects of RT given its anti-inflammatory properties. However, strong clinical evidence supporting its benefit is lacking [89]. Although there are plausible explanations for the benefit of aspirin, statin, and colchicine in prevention of RIHD, large-scale data on the use of these medications for prevention of RIHD are needed [90]. Finally, aggressive treatment of traditional cardiovascular risk factors and prior cardiovascular disease is important during and after RT.

\section{Conclusion}

Although modern radiation techniques, by reducing the dose delivered to the heart, have decreased the incidence of RIHD, they remain a major cause of morbidity and mortality among cancer survivors. In its early phase, RIHD may remain asymptomatic but can present symptomatically years after completion of RT. Prevention and early recognition is essential in the management of RIHD.

\section{Conflict of Interest Statement}

The authors have no conflicts of interest to declare.

\section{Funding Sources}

Own resources were used in this study.

\section{Author Contributions}

S.W.Y. and E.K. conceptualized and wrote the initial draft of the manuscript. N.L.P., A.D., S.H.L., J.A., Z.L., and J.B. reviewed and edited the manuscript. The manuscript has been read and approved by all authors.

\section{References}

1 Delaney G, Jacob S, Featherstone C, Barton $M$. The role of radiotherapy in cancer treatment: estimating optimal utilization from a review of evidence-based clinical guidelines. Cancer. 2005;104(6):1129-37.

2 Hooning MJ, Botma A, Aleman BM, Baaijens MH, Bartelink H, Klijn JG, et al. Long-term risk of cardiovascular disease in 10-year survivors of breast cancer. J Natl Cancer Inst. 2007;99(5):365-75.

3 van Nimwegen FA, Schaapveld M, Janus CP, Krol AD, Petersen EJ, Raemaekers JM, et al. Cardiovascular disease after Hodgkin lymphoma treatment: 40-year disease risk. JAMA Intern Med. 2015;175(6):1007-17.

4 Hancock SL, Tucker MA, Hoppe RT. Factors affecting late mortality from heart disease after treatment of Hodgkin's disease. JAMA. 1993;270(16):1949-55.

5 Veinot JP, Edwards WD. Pathology of radiation-induced heart disease: a surgical and autopsy study of 27 cases. Hum Pathol. 1996; 27(8):766-73.
6 Ng AK, Bernardo MP, Weller E, Backstrand $\mathrm{KH}$, Silver B, Marcus KC, et al. Long-term survival and competing causes of death in patients with early-stage Hodgkin's disease treated at age 50 or younger. J Clin Oncol. 2002;20(8):2101-8.

7 Miller KD, Nogueira L, Mariotto AB, Rowland JH, Yabroff KR, Alfano CM, et al. Cancer treatment and survivorship statistics, 2019. CA Cancer J Clin. 2019;69(5):363-85.

8 Al-Kindi SG, Oliveira GH. Incidence and trends of cardiovascular mortality after common cancers in young adults: analysis of surveillance, epidemiology and end-results program. World J Cardiol. 2016;8(6):368-74.

9 Rutqvist LE, Rose C, Cavallin-Ståhl E. A systematic overview of radiation therapy effects in breast cancer. Acta Oncol. 2003;42(5-6):532-45.

10 Underberg RW, Lagerwaard FJ, Slotman BJ, Cuijpers JP, Senan S. Benefit of respirationgated stereotactic radiotherapy for stage I lung cancer: an analysis of 4DCT datasets. Int J Radiat Oncol Biol Phys. 2005;62(2):554-60.
11 Milgrom SA, Varghese B, Gladish GW, Choi $\mathrm{AD}$, Dong W, Patel ZS, et al. Coronary artery dose-volume parameters predict risk of calcification after radiation therapy. J Cardiovasc Imaging. 2019;27(4):268-79.

12 Frankenberg D, Brede HJ, Schrewe UJ, Steinmetz C, Frankenberg-Schwager M, Kasten G, et al. Induction of DNA double-strand breaks by $1 \mathrm{H}$ and $4 \mathrm{He}$ lons in primary human skin fibroblasts in the LET range of 8 to $124 \mathrm{keV} /$ microm. Radiat Res. 1999;151(5):540-9.

13 Armenian SH, Lacchetti C, Barac A, Carver J, Constine LS, Denduluri N, et al. Prevention and monitoring of cardiac dysfunction in survivors of adult cancers: American Society of Clinical Oncology clinical practice guideline. J Clin Oncol. 2017;35(8):893-911.

14 Wang K, Eblan MJ, Deal AM, Lipner M, Zagar TM, Wang Y, et al. Cardiac toxicity after radiotherapy for stage III non-small-cell lung cancer: pooled analysis of dose-escalation trials delivering 70-90 Gy. J Clin Oncol. 2017; 35(13):1387-94. 
15 Cheng YJ, Nie XY, Ji CC, Lin XX, Liu LJ, Chen $\mathrm{XM}$, et al. Long-term cardiovascular risk after radiotherapy in women with breast cancer. J Am Heart Assoc. 2017;6(5):e005633.

16 Martel MK, Sahijdak WM, Ten Haken RK, Kessler ML, Turrisi AT. Fraction size and dose parameters related to the incidence of pericardial effusions. Int J Radiat Oncol Biol Phys. 1998;40(1):155-61.

17 Simonetto C, Eidemüller M, Gaasch A, Pazos M, Schönecker S, Reitz D, et al. Does deep inspiration breath-hold prolong life? Individual risk estimates of ischaemic heart disease after breast cancer radiotherapy. Radiother Oncol. 2019;131:202-7.

18 Welsh B, Chao M, Foroudi F. Reducing cardiac doses: a novel multi-leaf collimator modification technique to reduce left anterior descending coronary artery dose in patients with left-sided breast cancer. J Med Radiat Sci. 2017;64(2):114-9.

19 Remouchamps VM, Vicini FA, Sharpe MB, Kestin LL, Martinez AA, Wong JW. Significant reductions in heart and lung doses using deep inspiration breath hold with active breathing control and intensity-modulated radiation therapy for patients treated with locoregional breast irradiation. Int J Radiat Oncol Biol Phys. 2003;55(2):392-406.

20 Tribble DL, Barcellos-Hoff MH, Chu BM, Gong EL. Ionizing radiation accelerates aortic lesion formation in fat-fed mice via SODinhibitable processes. Arterioscler Thromb Vasc Biol. 1999;19(6):1387-92.

21 King V, Constine LS, Clark D, Schwartz RG, Muhs AG, Henzler M, et al. Symptomatic coronary artery disease after mantle irradiation for Hodgkin's disease. Int J Radiat Oncol Biol Phys. 1996;36(4):881-9.

22 Hooning MJ, Botma A, Aleman BMP, Baaijens MHA, Bartelink H, Klijn JGM, et al. Long-term risk of cardiovascular disease in 10-year survivors of breast cancer. J Natl Cancer Inst. 2007;99(5):365-75.

23 Tamulevicius P, Wang M, Iliakis G. Homology-directed repair is required for the development of radioresistance during $S$ phase: interplay between double-strand break repair and checkpoint response. Radiat Res. 2007;167(1): $1-11$.

24 Rutqvist LE, Johansson $\mathrm{H}$. Mortality by laterality of the primary tumour among 55,000 breast cancer patients from the Swedish Cancer Registry. Br J Cancer. 1990;61(6):866-8.

25 Aleman BMP, van den Belt-Dusebout AW, De Bruin ML, van 't Veer MB, Baaijens MHA, de Boer JP, et al. Late cardiotoxicity after treatment for Hodgkin lymphoma. Blood. 2006;109(5):1878-86.

26 Weintraub NL, Jones WK, Manka D. Understanding radiation-induced vascular disease. J Am Coll Cardiol. 2010;55(12):1237-9.

27 Ebrahimian TG, Beugnies L, Surette J, Priest $\mathrm{N}$, Gueguen Y, Gloaguen C, et al. Chronic exposure to external low-dose gamma radiation induces an increase in anti-inflammatory and anti-oxidative parameters resulting in athero- sclerotic plaque size reduction in $\mathrm{ApoE}(-/-)$ mice. Radiat Res. 2018;189(2):187-96.

28 Halle M, Gabrielsen A, Paulsson-Berne G, Gahm C, Agardh HE, Farnebo F, et al. Sustained inflammation due to nuclear factorkappa $B$ activation in irradiated human arteries. J Am Coll Cardiol. 2010;55(12):1227-36.

29 Venkatesulu BP, Mahadevan LS, Aliru ML, Yang X, Bodd MH, Singh PK, et al. Radiationinduced endothelial vascular injury: a review of possible mechanisms. JACC Basic Transl Sci. 2018;3(4):563-72.

30 Przybyszewski WM, WidełWidel M, Rzeszowska-Wolny J. Cardiotoxic consequences of ionizing radiation and anthracyclines. Postepy Hig Med Dosw. 2006;60:397-405.

31 Linard C, Marquette C, Mathieu J, Pennequin A, Clarençon D, Mathé D. Acute induction of inflammatory cytokine expression after gamma-irradiation in the rat: effect of an NF-kappaB inhibitor. Int J Radiat Oncol Biol Phys. 2004;58(2):427-34.

32 Prabhakarpandian B, Goetz DJ, Swerlick RA, Chen X, Kiani MF. Expression and functional significance of adhesion molecules on cultured endothelial cells in response to ionizing radiation. Microcirculation. 2001;8(5):355-64.

33 Azzam EI, Jay-Gerin JP, Pain D. Ionizing radiation-induced metabolic oxidative stress and prolonged cell injury. Cancer Lett. 2012; 327(1-2):48-60.

34 Matsumura S, Wang B, Kawashima N, Braunstein S, Badura M, Cameron TO, et al. Radiation-induced CXCL16 release by breast cancer cells attracts effector T cells. J Immunol. 2008;181(5):3099-107.

35 Yusuf SW, Howell RM, Gomez D, Pinnix CC, Iliescu CA, Banchs J. Radiation-related heart and vascular disease. Future Oncol. 2015; 11(14):2067-76.

36 Yusuf SW, Sami S, Daher IN. Radiation-induced heart disease: a clinical update. Cardiol Res Pract. 2011 Feb 27;2011:317659.

37 Marks LB, Yu X, Prosnitz RG, Zhou SM, Hardenbergh PH, Blazing M, et al. The incidence and functional consequences of RT-associated cardiac perfusion defects. Int J Radiat Oncol Biol Phys. 2005;63(1):214-23.

38 Yusuf SW, Venkatesulu BP, Mahadevan LS, Krishnan S. Radiation-induced cardiovascular disease: a clinical perspective. Front Cardiovasc Med. 2017;4:66.

39 Nielsen KM, Offersen BV, Nielsen HM, Vaage-Nilsen M, Yusuf SW. Short and long term radiation induced cardiovascular disease in patients with cancer. Clin Cardiol. 2017;40(4):255-61.

40 Veeragandham RS, Goldin MD. Surgical management of radiation-induced heart disease. Ann Thorac Surg. 1998;65(4):1014-9.

41 Heidenreich PA, Hancock SL, Lee BK, Mariscal CS, Schnittger I. Asymptomatic cardiac disease following mediastinal irradiation. J Am Coll Cardiol. 2003;42(4):743-9.

42 Fukada J, Shigematsu N, Takeuchi H, Ohashi T, Saikawa Y, Takaishi H, et al. Symptomatic pericardial effusion after chemoradiation therapy in esophageal cancer patients. Int $\mathrm{J}$ Radiat Oncol Biol Phys. 2013;87(3):487-93.

43 Morton DL, Glancy DL, Joseph WL, Adkins PC. Management of patients with radiationinduced pericarditis with effusion: a note on the development of aortic regurgitation in two of them. Chest. 1973;64(3):291-7.

44 Caro-Codón J, Jiménez-Valero S, Galeote G, Sanchez-Recalde A, Moreno R. Radiation-induced coronary artery disease: useful insights from OCT. Int J Cardiol. 2016;202:535-6.

45 Taylor CW, Nisbet A, McGale P, Darby SC. Cardiac exposures in breast cancer radiotherapy: 1950s-1990s. Int J Radiat Oncol Biol Phys. 2007;69(5):1484-95.

46 Desai MY, Jellis CL, Kotecha R, Johnston DR, Griffin BP. Radiation-associated cardiac disease: a practical approach to diagnosis and management. JACC Cardiovasc Imaging. 2018;11(8):1132-49.

47 Darby SC, Ewertz M, McGale P, Bennet AM, Blom-Goldman U, Brønnum D, et al. Risk of ischemic heart disease in women after radiotherapy for breast cancer. N Engl J Med. 2013; 368(11):987-98.

48 Swerdlow AJ, Higgins CD, Smith P, Cunningham D, Hancock BW, Horwich A, et al. Myocardial infarction mortality risk after treatment for Hodgkin disease: a collaborative British cohort study. J Natl Cancer Inst. 2007; 99(3):206-14.

49 Reed GW, Masri A, Griffin BP, Kapadia SR, Ellis SG, Desai MY. Long-term mortality in patients with radiation-associated coronary artery disease treated with percutaneous coronary intervention. Circ Cardiovasc Interv. 2016;9(6):e003483.

$50 \mathrm{Wu} \mathrm{W}$, Masri A, Popovic ZB, Smedira NG, Lytle BW, Marwick TH, et al. Long-term survival of patients with radiation heart disease undergoing cardiac surgery: a cohort study. Circulation. 2013;127(14):1476-85.

51 Chang AS, Smedira NG, Chang CL, Benavides MM, Myhre U, Feng J, et al. Cardiac surgery after mediastinal radiation: extent of exposure influences outcome. J Thorac Cardiovasc Surg. 2007;133(2):404-13.

52 Saiki H, Moulay G, Guenzel AJ, Liu W, Decklever TD, Classic KL, et al. Experimental cardiac radiation exposure induces ventricular diastolic dysfunction with preserved ejection fraction. Am J Physiol Heart Circ Physiol. 2017;313(2):H392-h407.

53 Heidenreich PA, Hancock SL, Vagelos RH Lee BK, Schnittger I. Diastolic dysfunction after mediastinal irradiation. Am Heart J. 2005; 150(5):977-82.

54 Adams MJ, Lipsitz SR, Colan SD, Tarbell NJ, Treves ST, Diller L, et al. Cardiovascular status in long-term survivors of Hodgkin's disease treated with chest radiotherapy. J Clin Oncol. 2004;22(15):3139-48.

55 Larsen RL, Jakacki RI, Vetter VL, Meadows AT, Silber JH, Barber G. Electrocardiographic changes and arrhythmias after cancer therapy in children and young adults. Am J Cardiol. 1992;70(1):73-7. 
56 Nakao T, Kanaya H, Namura M, Ohsato K, Araki T, Ohka T, et al. Complete atrioventricular block following radiation therapy for malignant thymoma. Jpn J Med. 1990;29(1):10410.

57 Desai MY, Wu W, Masri A, Popovic ZB, Agarwal S, Smedira NG, et al. Increased aorto-mitral curtain thickness independently predicts mortality in patients with radiationassociated cardiac disease undergoing cardiac surgery. Ann Thorac Surg. 2014;97(4):134855.

58 Paven E, Cimadevilla C, Dilly MP, Lepage L, Verdonk C, Raffoul R, et al. Management of radiation-induced valvular heart disease in the modern area. Arch Cardiovas Dis Suppl. 2018;10(1):84.

59 King LJ, Hasnain SN, Webb JA, Kingston JE, Shafford EA, Lister TA, et al. Asymptomatic carotid arterial disease in young patients following neck radiation therapy for Hodgkin lymphoma. Radiology. 1999; 213(1):167-72.

60 Cheng SW, Ting AC, Lam LK, Wei WI. Carotid stenosis after radiotherapy for nasopharyngeal carcinoma. Arch Otolaryngol Head Neck Surg. 2000;126(4):517-21.

61 De Bruin ML, Dorresteijn LD, van't Veer MB, Krol AD, van der Pal HJ, Kappelle AC, et al. Increased risk of stroke and transient ischemic attack in 5-year survivors of Hodgkin lymphoma. J Natl Cancer Inst. 2009;101(13): 928-37.

62 Iannuzzi R, Metson R, Lofgren R. Carotid artery rupture after twice-a-day radiation therapy. Otolaryngol Head Neck Surg. 1989; 100(6):621-2.

63 Groarke JD, Tanguturi VK, Hainer J, Klein J, Moslehi JJ, Ng A, et al. Abnormal exercise response in long-term survivors of hodgkin lymphoma treated with thoracic irradiation: evidence of cardiac autonomic dysfunction and impact on outcomes. J Am Coll Cardiol. 2015;65(6):573-83.

64 Demissei BG, Freedman G, Feigenberg SJ, Plastaras JP, Maity A, Smith AM, et al. Early changes in cardiovascular biomarkers with contemporary thoracic radiation therapy for breast cancer, lung cancer, and lymphoma. Int J Radiat Oncol Biol Phys. 2019;103(4): 851-60.

65 Hughes-Davies L, Sacks D, Rescigno J, Howard S, Harris J. Serum cardiac troponin T levels during treatment of early-stage breast cancer. J Clin Oncol. 1995;13(10):2582-4.

66 Gomez DR, Yusuf SW, Munsell MF, Welsh JW, Liao Z, Lin SH, et al. Prospective exploratory analysis of cardiac biomarkers and electrocardiogram abnormalities in patients receiving thoracic radiation therapy with highdose heart exposure. J Thorac Oncol. 2014; 9(10):1554-60

67 Portaluri M, Petruzzelli MF, Tramacere F, Andreassi MG. B-type natriuretic peptide plasma level in 5-year breast cancer survivors after radiotherapy. Int J Radiat Biol. 2019; 95(2):201-6.
68 D’Errico MP, Petruzzelli MF, Gianicolo EA, Grimaldi L, Loliva F, Tramacere F, et al. Kinetics of B-type natriuretic peptide plasma levels in patients with left-sided breast cancer treated with radiation therapy: results after one-year follow-up. Int J Radiat Biol. 2015; 91(10):804-9.

69 Lancellotti P, Nkomo VT, Badano LP, BerglerKlein J, Bogaert J, Davin JL, et al. Expert consensus for multi-modality imaging evaluation of cardiovascular complications of radiotherapy in adults: a report from the European Association of Cardiovascular Imaging and the American Society of Echocardiography. J Am Soc Echocardiogr. 2013;26(9):1013-32.

70 Donovan EK, Dhesy-Thind S, Swaminath A, Leong D, Pond G, Voruganti S, et al. MEDiastinal Irradiation and CArdio-Toxic Effects (MEDICATE): exploring the relationship between cardiac irradiation and high sensitivity troponins. Clin Oncol. 2019;31(7):479-85.

71 Erven K, Jurcut R, Weltens C, Giusca S, Ector $\mathrm{J}$, Wildiers $\mathrm{H}$, et al. Acute radiation effects on cardiac function detected by strain rate imaging in breast cancer patients. Int J Radiat Oncol Biol Phys. 2011;79(5):1444-51.

72 Lo Q, Hee L, Batumalai V, Allman C, MacDonald P, Delaney GP, et al. Subclinical cardiac dysfunction detected by strain imaging during breast irradiation with persistent changes 6 weeks after treatment. Int J Radiat Oncol Biol Phys. 2015;92(2):268-76.

73 Greenland $\mathrm{P}$, Bonow RO, Brundage $\mathrm{BH}, \mathrm{Bu}-$ doff MJ, Eisenberg MJ, Grundy SM, et al. ACCF/AHA 2007 clinical expert consensus document on coronary artery calcium scoring by computed tomography in global cardiovascular risk assessment and in evaluation of patients with chest pain: a report of the American College of Cardiology Foundation Clinical Expert Consensus Task Force (ACCF/ AHA writing committee to update the 2000 expert consensus document on electron beam computed tomography). Circulation. 2007; 115(3):402-26.

74 Hardenbergh PH, Munley MT, Bentel GC, Kedem R, Borges-Neto S, Hollis D, et al. Cardiac perfusion changes in patients treated for breast cancer with radiation therapy and doxorubicin: preliminary results. Int J Radiat Oncol Biol Phys. 2001;49(4):1023-8.

75 Shoukat S, Zheng D, Yusuf SW. Cardiotoxicity related to radiation therapy. Cardiol Clin. 2019;37(4):449-58.

76 Virani SA, Dent S, Brezden-Masley C, Clarke B, Davis MK, Jassal DS, et al. Canadian Cardiovascular Society Guidelines for evaluation and management of cardiovascular complications of cancer therapy. Can J Cardiol. 2016; 32(7):831-41

77 Zamorano JL, Lancellotti P, Rodriguez Munoz D, Aboyans V, Asteggiano R, Galderisi M, et al. 2016 ESC Position Paper on cancer treatments and cardiovascular toxicity developed under the auspices of the ESC Committee for Practice Guidelines: the Task Force for cancer treatments and cardiovascular toxicity of the
European Society of Cardiology (ESC). Eur Heart J. 2016;37(36):2768-801.

78 Myrehaug S, Pintilie M, Tsang R, Mackenzie R, Crump M, Chen Z, et al. Cardiac morbidity following modern treatment for Hodgkin lymphoma: supra-additive cardiotoxicity of doxorubicin and radiation therapy. Leuk Lymphoma. 2008;49(8):1486-93.

79 Thorsen LB, Offersen BV, Danø H, Berg M, Jensen I, Pedersen AN, et al. DBCG-IMN: a population-based cohort study on the effect of internal mammary node irradiation in early node-positive breast cancer. J Clin Oncol. 2016;34(4):314-20.

80 Palaskas NN, Patel A, PatelYusuf SW. Radiation and cardiovascular disease. Ann Transl Med. 2019;7(Suppl 8):S371.

81 Maraldo MV, Brodin NP, Vogelius IR, Aznar MC, Munck Af Rosenschöld P, Petersen PM, et al. Risk of developing cardiovascular disease after involved node radiotherapy versus mantle field for Hodgkin lymphoma. Int J Radiat Oncol Biol Phys. 2012;83(4):1232-7.

82 Aznar MC, Maraldo MV, Schut DA, Lundemann M, Brodin NP, Vogelius IR, et al. Minimizing late effects for patients with mediastinal Hodgkin lymphoma: deep inspiration breath-hold, IMRT, or both? Int J Radiat Oncol Biol Phys. 2015;92(1):169-74.

83 Maraldo MV, Specht L. A decade of comparative dose planning studies for early-stage Hodgkin lymphoma: what can we learn? Int $J$ Radiat Oncol Biol Phys. 2014;90(5):1126-35.

84 Lin SH, Hobbs BP, Verma V, Tidwell RS, Smith GL, Lei X, et al. Randomized phase IIB trial of proton beam therapy versus intensitymodulated radiation therapy for locally advanced esophageal cancer. J Clin Oncol. 2020; 38(14):1569-79.

$85 \mathrm{Yu} \mathrm{JM}$, Hsieh MC, Qin L, Zhang J, Wu SY. Metformin reduces radiation-induced cardiac toxicity risk in patients having breast cancer. Am J Cancer Res. 2019;9(5):1017-26.

$86 \mathrm{Xu} \mathrm{G}, \mathrm{Wu} \mathrm{H}$, Zhang J, Li D, Wang Y, Wang $\mathrm{Y}$, et al. Metformin ameliorates ionizing irradiation-induced long-term hematopoietic stem cell injury in mice. Free Radic Biol Med. 2015;87:15-25.

87 Boulet J, Peña J, Hulten EA, Neilan TG, Dragomir A, Freeman C, et al. Statin use and risk of vascular events among cancer patients after radiotherapy to the thorax, head, and neck. J Am Heart Assoc. 2019;8(13):e005996.

88 Zhang K, He X, Zhou Y, Gao L, Qi Z, Chen J, et al. Atorvastatin ameliorates radiation-induced cardiac fibrosis in rats. Radiat Res. 2015;184(6):611-20.

89 O'Herron T, Lafferty J. Prophylactic use of colchicine in preventing radiation induced coronary artery disease. Med Hypotheses. 2018;111:58-60.

90 Camara Planek MI, Silver AJ, Volgman AS, Okwuosa TM. Exploratory review of the role of statins, colchicine, and aspirin for the prevention of radiation-associated cardiovascular disease and mortality. J Am Heart Assoc. 2020;9(2):e014668. 